months have this repeated at three monthly intervals.

(5) The resuscitation training of medical and nursing staff will now be on a compulsory rather than voluntary basis.

BAzIRE, (1995) The Psychotropic Drug Directory. Salisbury: Quay Books.

THOMPSON, C. (1994) Consensus Statement: the use of high dose antipsychotic medication. Britlsh Journal of Psychiatry, 164, 448-458.

ROSS J. HAMILTON

ANDREW D. WELLS

Royal Cornhill Hospital, Aberdeen AB25 2ZH

\section{The research option for MRCPsych eramination}

Sir: Candidates for the MRCPsych Part II examination may, subject to certain conditions, submit a dissertation describing a research project carried out by themselves or jointly. This dissertation, if successful, will replace the essay paper of the examinations. The College is undoubtedly aware of the under-usage of the research option by trainees. Obviously the College's aim in encouraging trainees to acquire a more searching and critical approach and to foster interest in clinical data, literature, the teaching of psychiatric practice and research (The Royal College of Psychiatrists, 1995) is not met.

$A$ title and brief outline of the proposed research project must be submitted to the Court of Electors at least 15 months before the examination. This period could be reduced. According to the College regulations, candidates will be informed prior to the date of written papers whether their dissertation has reached the required standard, but no time limit is given. This decision will affect the candidates' preparation so they would like to be informed at specific times prior to the examination. Finally, publishing abstracts of accepted research will encourage other trainees and give them an idea about standards accepted by the College.

THE Royal Coluege of PSYchiatrists (1995) General Information and Regulations for the MRCPsych Examination. London: RCP.

ASHRAF NASR

King's Norton, Birmingham

Sir: Your correspondent rightly asserts that the research option for candidates for Membership of the College by examination has been very infrequently taken up. The research option has not been effective in requiring trainees to acquaint themselves with research methodology and to develop a critical and balanced approach to the psychiatric literature. Partly on this account the Examinations Sub-Committee of the Court of Electors is developing a "Critical Review" paper to test these abilities. This is likely to be introduced in the Autumn of 1997 or the Spring of 1998. The paper is currently being developed, using experiences of this kind of paper in other Colleges and in Untversities. The new paper will replace the Short Answer paper which principally examines factual knowledge and in this respect overlaps the areas examined by the Multiple Choice Question paper.

As yet, no decision has been made about the future of the research option in the examinations for the MRCPsych. Preparing a dissertation engages the trainee in research procedures in a very direct way which is impossible to replace by a written paper. Probably the most important requirement for the preparation of a dissertation as training in research is that satisfactory arrangements are made for supervision. This and other aspects of research training are very difficult to arrange on a national, or even international basis, and it seems unlikely that a dissertation will ever become a compulsory part of the requirements for Membership of the College. The development of Masters degrees in Psychiatry which require a dissertation probably provide a more satisfactory way of making this experience available to psychiatric trainees; untversities have staff with suitable experience to act as supervisors.

\section{R. MINDHAM Chief Examiner, Royal College of Psychiatrists}

\section{Terminology; learning difficulties or mental retardation}

Sir: One can emphathise with R. Denson (Psychiatric Bulletin. May 1996, 20, 309-310). The attempt to use appropriate and understandable terminology in this field can leave one speechless. As clinicians we must use terminology that is acceptable to our patients, yet allows internationally comparattve data to accrue which enhances clinical practice. Efforts to be politically correct often fail on both accounts.

In Ireland, advocates with the disability in question prefer the term learning disability. However, this term is either meaningless or conveys the wrong meaning when used in conversations with other groups or with colleagues from outside these islands. Mental handicap is the term used by the national umbrella organisation of service providers and parents and friends groups (NAMHI). However, the docu- 